\title{
Meio Ambiente e Água Sob a Perspectiva da Teoria das Representações Sociais
}

Environment And Water From The Perspective Of The Social Representations Theory

Medio Ambiente Y Agua Bajo La Perspectiva De La Teoría De Las Representaciones Sociales

Gislei Mocelin Polli \& Brigido Vizeu Camargo

Universidade

Federal de Santa Catarina
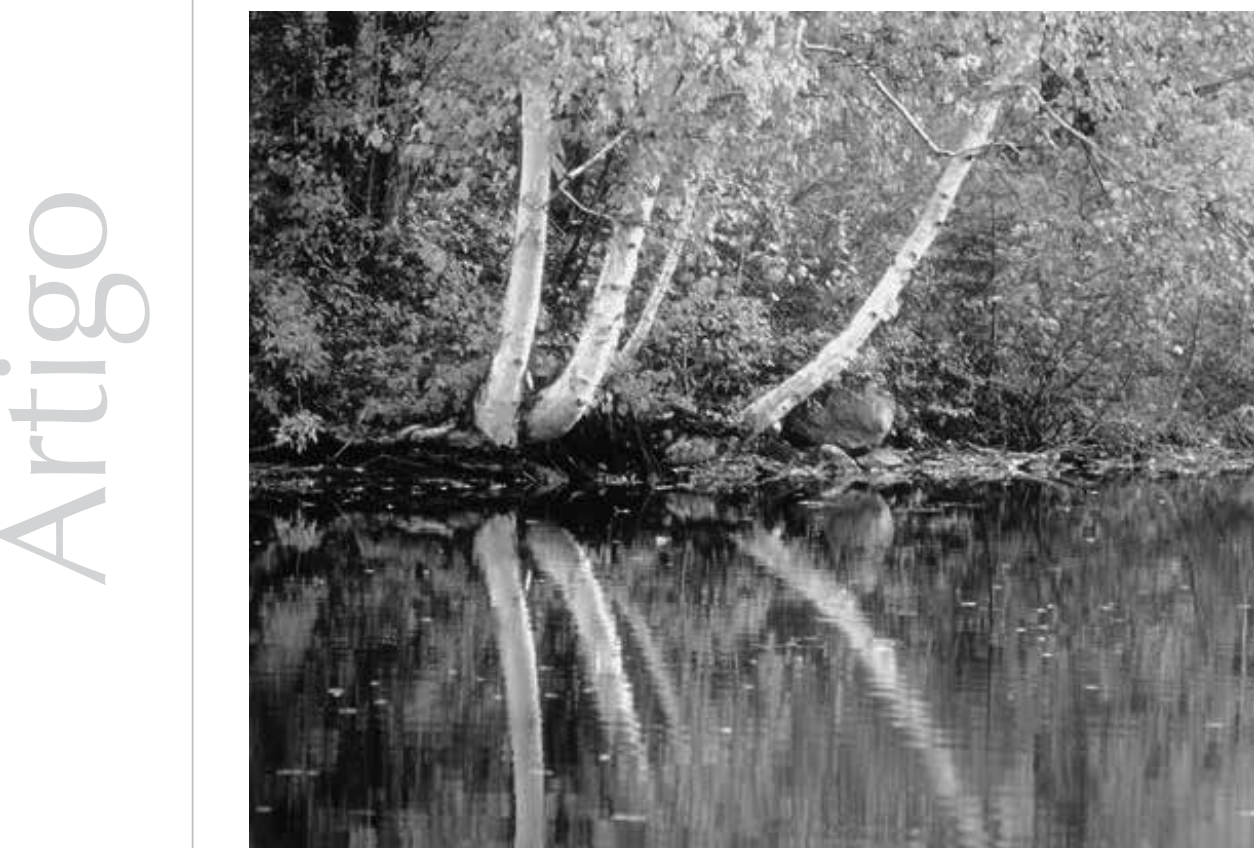
Resumo: A teoria das representações sociais tem papel fundamental na busca da compreensão do pensamento social sobre o meio ambiente e os recursos naturais, pois permite compreender como os seres humanos se relacionam com tais recursos. Este estudo teve por objetivo identificar a dimensão informacional das representações sociais da água e do meio ambiente, bem como a relação existente entre elas, e, para tanto, 150 participantes responderam a questões abertas sobre o que sabiam acerca dos dois objetos. $\mathrm{O}$ material textual das respostas foi submetido a uma classificação hierárquica descendente, com o emprego do programa informático ALCESTE. Esse procedimento permitiu identificar que a representação social do meio ambiente é composta por quatro classes que destacam os problemas ambientais, a necessidade de educação para o cuidado, a importância que ele assume para a vida e as suas características. A representação da água, também composta por quatro classes, considera-a importante para a vida, aborda a situação da água no Planeta, os cuidados de que necessita e também a sua utilização. Algumas relações puderam ser verificadas entre as duas representações. O conteúdo identificado nas classes não se limitou apenas à dimensão informacional das representações, mas extrapolou-a, de modo que ambas as representações sociais foram estudadas em seus aspectos globais.

Palavras-chave: Representações sociais. Ambiente. Água. Ecologia comportamental. Psicologia ambiental.

Abstract: The theory of social representations has a fundamental role in the pursuit of the comprehension on the social thinking about the environment and the natural resources, for it allows to understand how humans relate with such resources. This study aimed to identify the size of informational social representations on water and environment, as well as the relationship between them, for 150 participants who answered open questions on what they knew about the two issues. The textual material of the responses was submitted to a descending hierarchical classification, using the software ALCESTE. This procedure allowed us to identify that the social representation of environment consists of four classes that highlight the environmental problems, the educational needs for care, the importance it has for life, and its characteristics. The water representation, also composed of four classes, considered water important for life, deals with the water situation on the planet, the necessary care, and also the uses of water. Some relations could be verified between the two representations. The content identified in the classes was not limited to the informational dimension of the representation, but extrapolated it, so both representations were studied in their global aspects.

Keywords: Social representations. Environment. Water. Behavioral ecology. Environmental psychology.

Resumen: La teoría de las representaciones sociales tiene un papel fundamental en la búsqueda de la comprensión del pensamiento social sobre el medio ambiente y los recursos naturales, pues permite comprender como los seres humanos se relacionan con tales recursos. Este estudio tuvo por objetivo identificar la dimensión informacional de las representaciones sociales del agua y del medio ambiente, así como la relación existente entre ellas, y, para tanto, 150 participantes contestaron a preguntas abiertas sobre lo que sabían acerca de los dos objetos. El material textual de las respuestas fue sometido a una clasificación jerárquica descendiente, con el empleo del programa informático ALCESTE. Ese procedimiento permitió identificar que la representación social del medio ambiente está compuesta de cuatro clases que destacan los problemas ambientales, la necesidad de educación para el cuidado, la importancia que él asume para la vida y sus características. La representación del agua, también compuesta de cuatro clases, la considera importante para la vida, aborda la situación del agua en el Planeta, los cuidados de que necesita y también su utilización. Algunas relaciones pudieron ser verificadas entre las dos representaciones. El contenido identificado en las clases no se limitó solamente a la dimensión informacional de las representaciones, sino que la extrapoló, de modo que ambas representaciones sociales fueron estudiadas en sus aspectos globales. Palabras clave: Representaciones sociales. Ambiente. Agua. Ecologia conductual. Psicología ambiental.

Na vida cotidiana, as pessoas buscam compreender o mundo ao seu redor, e, para tanto, apropriam-se dos mais diversos conhecimentos de modo a criar explicações para a realidade que as rodeia. Todos somos cientistas amadores e construímos teorias baseadas em informações que circulam na sociedade. Tais teorias têm o objetivo de tornar o mundo mais conhecido, mais controlável (Moscovici, 1982). Esse saber apropriado e reproduzido, também conhecido como senso comum, é o saber das representações sociais, que são ativadas na vida social, e seus elementos constituem um saber que diz algo sobre a realidade; elas se caracterizam por uma forma de conhecimento elaborado e partilhado socialmente que resulta em uma realidade comum a um grupo social, resultam em um saber do senso comum que, apesar de diferenciado do conhecimento científico, 


\footnotetext{
A teoria das representações sociais busca compreender como as representações sociais são formadas, como o discurso popular ganha forma a partir dos conhecimentos divulgados pela mídia e pela comunicação de maneira geral, busca compreender como o pensamento social se origina e é disseminado a partir da comunicação social, sendo que o pensamento social influencia a realidade $e \mathrm{o}$ modo de vida das pessoas (Jodelet, 2001; Moscovici, 1982).
}

pode ser influenciado por este (Jodelet, 2001).

A teoria das representações sociais busca compreender como as representações sociais são formadas, como o discurso popular ganha forma a partir dos conhecimentos divulgados pela mídia e pela comunicação de maneira geral, busca compreender como o pensamento social se origina e é disseminado a partir da comunicação social, sendo que o pensamento social influencia a realidade e o modo de vida das pessoas (Jodelet, 2001; Moscovici, 1982).

As representações sociais são compostas por três dimensões: a informacional, que é o conhecimento que o grupo possui sobre o objeto da representação, constitui um conhecimento consistente sobre o objeto social representado; o campo representacional, a imagem que a representação adquire frente a esse grupo, é uma espécie de ilustração do objeto representado, e a dimensão atitude refere-se a uma valoração apreciativa e a uma orientação para a ação quanto ao objeto da representação. As três dimensões da representação social permitem compreender seu conteúdo e seu sentido (Moscovici, 1978).

As práticas sociais, por sua vez, estão intrinsecamente relacionadas com as representações. Conforme Guimelli (1993), a representação social funciona como um guia para a ação, e uma das suas funções essenciais é a de contribuir para a formação de processos que orientam a comunicação e o comportamento social. Abric (1994) definiu práticas sociais como um sistema de ações estruturadas socialmente e que tem origem na relação com os papéis socialmente desempenhados. Desse modo, pode-se considerar que as representações são criadas sobre o mundo que nos cerca, e influenciam diretamente as ações executadas cotidianamente sobre esse mundo, daí a importância que a teoria das representações sociais assume nos estudos sobre o meio ambiente e seus componentes, pois as representações elaboradas sobre o ambiente influenciam a relação que será estabelecida com ele, a forma de pensar sobre o ambiente e sobre os aspectos ambientais que cercam a pessoa, bem como influenciam o próprio comportamento, ou práticas sociais, que irá adotar em relação a esse meio. As representações assumem o papel de organizar e de estruturar o real em um sistema cognitivo coerente que permite que a pessoa possa entender o mundo e atuar sobre ele. As características pessoais, as experiências passadas e presentes na relação com o ambiente, incluindo a cultura e a antecipação do que possa acontecer no futuro, determinam esse sistema (Moser, Ratiu, \& Vanssay, 2005); seu estudo possibilita a compreensão acerca do conhecimento que a população possui sobre a atual situação do Planeta no que diz respeito aos recursos naturais, e permite entender como o conhecimento científico é apropriado pelas pessoas no discurso social e como se torna conteúdo comum do saber popular (Félonneau, 2003; Jodelet, 1996, 2002).

Os modos de pensar sobre o meio ambiente vêm sendo modificados ao longo dos anos, e, atualmente, predomina uma visão baseada na preocupação com os cuidados ambientais (Pinheiro, 2003). No passado, o meio ambiente era visto como provedor, e sua função era servir aos seres humanos, mas a emergência das questões ambientais vem, ao longo do tempo, mudando essa visão (SilvaFilho, Gavronski, Oliveira, Tocchetto, Araújo, Torres, et al. 2007). Essa mudança está relacionada à mudança paradigmática que vem ocorrendo na sociedade. O paradigma social dominante (human exemptionalism paradigm - HEP), também chamado de visão antropocêntrica, em que crenças de que a natureza é algo que pode ser controlado, vem dando lugar a um novo paradigma 
ambiental (new environmental paradigm $N E P)$, também chamado de visão ecológica, ou paradigma ecológico, que envolve crenças de que o direito à vida sob qualquer forma é fundamental, o equilíbrio da natureza é delicado, os recursos naturais são limitados e, portanto, necessitam de cuidado e de equilíbrio (Nascimento-Schulze, Fragnani, Carboni, \& Maliska, 2002).

A mudança de paradigma ocorre lentamente, e cognições compatíveis com o primeiro tipo de crenças coexistem com outras compatíveis com o segundo tipo mencionado. Por tais crenças serem compartilhadas socialmente através da comunicação social, é esperado que o momento de transição promova reflexos nas representações sociais do meio ambiente e dos elementos naturais que, em consequência da mudança de paradigma ambiental, podem estar passando por modificações.

No Brasil, alguns estudos já foram realizados com o objetivo de identificar as representações sociais do meio ambiente. Embora nenhum desses estudos tenha focalizado a sua dimensão informacional, seus resultados servem para balizar a análise dos resultados encontrados no presente estudo.

Reigota (2004) publicou uma coletânea de artigos em um livro denominado Meio Ambiente e Representação Social. O autor verificou que as representações sociais do meio ambiente eram ainda embrionárias, já que os dados haviam sido coletados entre 1991 e 1993, quando as discussões ambientais recebiam menor ênfase ou mesmo divulgação menos efetiva. As representações sociais identificadas sobre o ambiente mostraram-se bastante naturalistas. Além dessa representação majoritária, o autor também identificou duas outras representações sociais do meio ambiente. Uma foi denominada pelo autor espacial, que se refere ao meio ambiente como o local onde os seres vivos habitam; a outra se refere aos elementos que o circundam, sejam seres vivos ou inanimados.

Buscando articular o conhecimento sobre as representações sociais da natureza e do meio ambiente, Nascimento-Schulze (2000) realizou uma pesquisa empírica com moradores locais, com turistas e com agentes de turismo de Florianópolis, Santa Catarina. Os resultados encontrados pela pesquisadora indicaram que os três grupos representavam a natureza e o meio ambiente de forma bastante naturalista, além de terem revelado uma forte preocupação com a preservação da natureza, principalmente por parte dos moradores locais.

As representações sociais sobre o meio ambiente de alunos da quarta série do ensino fundamental foram investigadas por Martinho e Talamoni (2007), que encontraram representações naturalistas e antropocêntricas. As representações naturalistas foram caracterizadas por apresentarem noções sobre os aspectos naturais do meio ambiente, e as antropocêntricas são aquelas que se pautam na visão do meio ambiente e dos elementos naturais voltados para a satisfação das necessidades humanas. A visão naturalista predominou em relação à visão antropocêntrica no grupo de estudantes investigado.

Considerando-se a urgência que as questões ambientais apresentam no cenário global atual, principalmente aquelas que se referem à água, este estudo objetivou compreender as informações que as pessoas possuem sobre o meio ambiente e a água, como forma de identificar a dimensão informacional de ambas as representações sociais bem como a relação existente entre elas. 


\section{Método}

\section{Participantes}

Responderam ao instrumento de coleta de dados 150 participantes: 25 mulheres e 25 homens com idade entre 18 e 29 anos (faixa etária 1), 25 mulheres e 25 homens com idade entre 30 e 59 anos (faixa etária 2), 25 mulheres e 25 homens com 60 anos ou mais (faixa etária 3). Todos os respondentes foram contatados nas dependências do SESC (Serviço Social do Comércio) na cidade de Florianópolis. O local foi escolhido por possibilitar certa equivalência educacional e socioeconômica, independentemente da faixa etária dos participantes.

O controle da amostra em relação à faixa etária se deve ao fato de que as diferentes faixas etárias foram expostas de forma distinta aos diferentes paradigmas ambientais, sendo que os respondentes da faixa etária 3 (60 anos ou mais) tiveram sua educação formal realizada no período em que o paradigma dominante era o antropocêntrico; os respondentes da faixa etária 2 (de 30 até 59 anos) tiveram sua educação formal realizada em um período de transição entre os paradigmas, e os respondentes da faixa etária 1 (18 até 29 anos) foram educados sob a prevalência do paradigma ecológico.

\section{Instrumentos}

O instrumento foi composto de diferentes tipos de questões, e, neste estudo, serão trabalhadas as questões relativas à identificação das informações que os respondentes possuíam sobre o meio ambiente e a água. Foram formuladas questões abertas, em que deveriam discorrer sobre o que sabiam sobre os elementos, e questões fechadas, em que deveriam apontar as fontes de tais informações. As respostas sobre estas últimas foram utilizadas para contextualizar a dimensão informacional das representações identificadas. Na última parte do instrumento, foram apresentadas questões sobre a caracterização dos participantes.

\section{Procedimento}

A coleta de dados foi realizada nas dependências do SESC-SC com autorização prévia da instituição. Os respondentes foram convidados a participar durante a realização de atividades variadas, como salas de espera, curso de idiomas, etc. Todos os respondentes foram esclarecidos sobre o sigilo em relação aos dados individuais e assinaram um Termo de Consentimento Livre e Esclarecido para atestarem sua participação voluntária. A realização do estudo foi previamente autorizada pelo Comitê de Ética em Pesquisa com Seres Humanos da UFSC.

A maior parte dos participantes respondeu de forma escrita ao instrumento, sendo que apenas algumas pessoas de idade elevada e com dificuldade para leitura responderam em forma de entrevista.

\section{Análise de dados}

Os dados foram analisados com o auxílio do programa informático ALCESTE (Camargo, 2005), e as respostas dadas a cada uma das questões foram transcritas e deram origem a dois corpora de análise, um com a temática água, e outro com a temática meio ambiente. As respostas tinham entre três e quatro linhas em média, de modo que cada unidade de contexto inicial (UCI) foi considerada uma unidade de contexto elementar (UCE).

Para análise das respostas, foi utilizada a técnica de classificação hierárquica descendente (CHD). Conforme Camargo (2005), a CHD consiste na realização de uma análise lexicográfica de classificação de segmentos de texto, que gera classes que se caracterizam pelo compartilhamento de significados desses segmentos de texto. 
As questões sobre as fontes de informação dos respondentes foram analisadas em termos de quantidade, dando-se destaque para as fontes de informação consideradas mais utilizadas pela maior parte dos respondentes.

\section{Resultados}

\section{Representação social do meio ambiente}

A composição do corpus para análise da representação social do meio ambiente se deu através da transcrição das respostas à seguinte questão: Gostaríamos que você escrevesse abaixo, se possível utilizando todo o espaço, o que de mais importante você sabe sobre o meio ambiente. Um dos participantes não apresentou nenhuma resposta à presente questão, de modo que houve 149 respostas.

Esse corpus foi composto por 149 UCls, que deram origem a 149 UCEs que continham 1221 palavras diferentes. Para análise, foram consideradas as palavras com frequência igual ou superior a quatro e qui-quadrado com significância estatística $\left(\mathrm{X}^{2}>3,84, \mathrm{gl}=1\right)$. A taxa de UCEs retidas para análise foi de $93 \%$. A CHD deu origem a quatro classes compostas por segmentos de texto diferentes entre si.

Dentre as palavras consideradas, 11 compuseram a primeira classe, 15, a segunda, 9, a terceira, e 22, a quarta. A distribuição das palavras por classes pode ser visualizada na Figura 1.

\begin{tabular}{|c|c|c|c|c|c|c|c|c|c|c|c|}
\hline & & & & & & & & & & & \\
\hline \multicolumn{3}{|c|}{$\begin{array}{l}\text { Classe } 1 \\
\text { Problemas Ambientais } \\
\text { Número de UCES: } 21 \text { (15\% } \\
\text { do corpus) } \\
\text { Varável associada: } \\
\text { Faixa etária } 3\end{array}$} & \multicolumn{3}{|c|}{$\begin{array}{l}\text { Classe } 3 \\
\text { Educar para cuidar } \\
\text { Número de UCES: } 26 \\
\text { (20\% do corpus) } \\
\text { Nenhuma varúvel associada }\end{array}$} & \multicolumn{3}{|c|}{$\begin{array}{l}\text { Classe } 2 \\
\text { Importante para vida } \\
\text { Número de UCES: } 34 \\
\text { (24\% do corpus) } \\
\text { Nentouma varável lassociada }\end{array}$} & \multicolumn{3}{|c|}{$\begin{array}{l}\text { Classe } 4 \\
\text { Características } \\
\text { Número de UCES: } 56 \\
\text { (41\% do corpus) } \\
\text { Nentuma varível associada }\end{array}$} \\
\hline $\begin{array}{l}\text { Palavra } \\
\text { Fio } \\
\text { Árvore } \\
\text { Cuidar } \\
\text { Amazônia } \\
\text { Plantas } \\
\text { Desmatamento } \\
\text { Proteçäo } \\
\text { Principalmente } \\
\text { Cidade } \\
\text { Esgoto } \\
\text { Problerma }\end{array}$ & $\begin{array}{r}\text { Frey } \\
12 \\
8 \\
7 \\
6 \\
6 \\
6 \\
5 \\
5 \\
4 \\
3 \\
3\end{array}$ & $\begin{array}{r}x^{2} \\
37 \\
21 \\
6 \\
23 \\
12 \\
10 \\
29 \\
17 \\
8 \\
12 \\
12\end{array}$ & $\begin{array}{l}\text { Palawra } \\
\text { Lixo } \\
\text { Cuidar } \\
\text { Fazer } \\
\text { Reciclagem } \\
\text { Jogam } \\
\text { Saber } \\
\text { Limpa } \\
\text { Falta } \\
\text { Educą̧a a }\end{array}$ & $\begin{array}{r}\text { Freq } \\
15 \\
10 \\
9 \\
7 \\
7 \\
6 \\
6 \\
6 \\
4\end{array}$ & $\begin{array}{r}\boldsymbol{x}^{2} \\
33 \\
8 \\
10 \\
24 \\
20 \\
25 \\
8 \\
6 \\
12\end{array}$ & 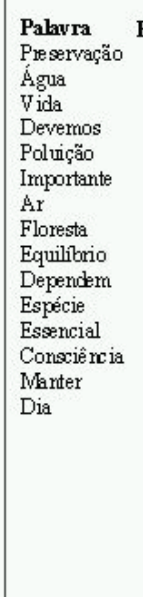 & $\begin{array}{r}\text { Freq } \\
20 \\
13 \\
13 \\
10 \\
9 \\
9 \\
8 \\
7 \\
7 \\
6 \\
5 \\
5 \\
4 \\
4 \\
4\end{array}$ & $\begin{array}{r}x^{2} \\
41 \\
17 \\
8 \\
7 \\
16 \\
8 \\
26 \\
8 \\
6 \\
5 \\
16 \\
9 \\
9 \\
6 \\
4\end{array}$ & $\begin{array}{l}\text { Palavra } \\
\text { Meio ambiente } \\
\text { Natureza } \\
\text { Humaros } \\
\text { Seres } \\
\text { Viver } \\
\text { Meio } \\
\text { Existe } \\
\text { Todos } \\
\text { Homem } \\
\text { Arimais } \\
\text { Natural } \\
\text { Preocuparąo } \\
\text { Grarde } \\
\text { Ganância } \\
\text { Respeito } \\
\text { Parte } \\
\text { Espaço } \\
\text { Sistema } \\
\text { Vivos } \\
\text { Responsíveis } \\
\text { Mareira } \\
\text { Saudível }\end{array}$ & $\begin{array}{r}\text { Freq } \\
58 \\
21 \\
20 \\
16 \\
16 \\
15 \\
13 \\
13 \\
12 \\
11 \\
10 \\
10 \\
8 \\
6 \\
6 \\
6 \\
5 \\
5 \\
5 \\
4 \\
4 \\
4\end{array}$ & $\begin{array}{r}\boldsymbol{x}^{2} \\
10 \\
13 \\
13 \\
13 \\
9 \\
5 \\
18 \\
8 \\
12 \\
4 \\
6 \\
4 \\
4 \\
9 \\
6 \\
4 \\
8 \\
6 \\
5 \\
6 \\
5 \\
5\end{array}$ \\
\hline
\end{tabular}

Figura 1. Dendograma da análise hierárquica descendente sobre as informações dos respondentes sobre o meio ambiente 
Através da Figura 1, é possível observar que houve uma primeira repartição do corpus em dois subcorpora que, em seguida, foram subdivididos, dando origem a quatro classes. O primeiro subcorpora deu origem às classes 1 e 3, e o segundo, às classes 2 e 4. Em cada uma das classes, foi apresentado o seu título, o número de UCEs que as compunham e as variáveis descritivas associadas, quando havia, e as palavras que as compunham com as respectivas frequências e valor de qui-quadrado.

\section{Problemas relacionados ao meio ambiente}

A classe 1 foi composta por 21 UCEs, o que corresponde a $15 \%$ de todo o corpus, e está ligada aos respondentes da faixa etária 3 (60 anos ou mais). Essa classe tem seu conteúdo agrupado ao redor de palavras como rio, proteção, Amazônia, esgoto e desmatamento, entre outras, e seu conteúdo trata dos problemas relacionados ao meio ambiente.

Essa classe considera os problemas ambientais importantes na representação social do meio ambiente, e revela-se preocupada com a atual situação dos recursos naturais. Alguns recortes das respostas encontradas ilustram esse conhecimento:

Queimadas, derrubada de árvores na Amazônia, devastação, cortam sem reflorestar.

Mudanças climáticas provenientes da contaminação do ambiente por poluentes que vêm causando uma transformação global planetária; degelo, contaminação ambiental.

A partir da ligação dessa classe com a variável explicativa faixa etária 3, pode-se compreender que as pessoas de faixa etária mais elevada (60 anos ou mais) identificam problemas relacionados ao meio ambiente, bem como algumas de suas causas e suas possíveis consequências.

\section{Meio ambiente importante para vida}

A classe 2 foi composta por 34 UCEs, o que corresponde a $24 \%$ das UCE analisadas. Não está associada a nenhuma variável explicativa, e identifica o meio ambiente como importante para a manutenção da vida em geral. As palavras preservação, poluição, consciência e essencial, entre outras, indicam tal informação. Elementos naturais considerados relevantes para a manutenção da vida estão presentes nessa classe, através das palavras ar, água e floresta.

Através da análise dessa classe, é possível identificar a relação estabelecida pelos respondentes entre o equilíbrio do meio ambiente e a manutenção da vida. Algumas respostas demonstram essa associação:

A preservação do meio ambiente é essencial para a nossa sobrevivência, pois com a poluição do ar, a destruição das florestas e o consumo da água do Planeta, perdemos o que de mais essencial temos para sobreviver.

Que toda vida no Planeta depende do meio ambiente, pois sem água, sem ar, sem alimentos, nada conseguiria sobreviver.

Essa classe reconhece o valor que o meio ambiente e os elementos naturais assumem como geradores de vida e a necessidade de manter a qualidade do meio ambiente para que a vida possa continuar a existir sobre o planeta Terra; não está associada a nenhuma variável, de modo que todos os respondentes compõem o conhecimento dessa classe. Por esse motivo, pode-se dizer que todos eles reconhecem essa característica do meio ambiente, como promotora da vida. 


\section{Educar para cuidar do meio ambiente}

A classe número 3 foi formada por 26 UCEs, o que corresponde a $20 \%$ do total de UCEs analisadas, e não está associada a nenhuma variável explicativa. A classe 3 é composta por elementos que indicam a importância da educação para que exista o cuidado com o meio ambiente, e elementos como saber, educação, cuidar e fazer, entre outros, ilustram tal importância. A presença de palavras como reciclar, jogar, usar e limpar, entre outras, dão exemplo das ações humanas que influenciam o cuidado com o meio ambiente.

O conteúdo dessa classe remete a ações voltadas para o cuidado com o meio ambiente, e destaca que tais ações podem ser efetivas através da educação das pessoas para o cuidado ambiental. Um trecho de resposta ilustra a forma como esse conhecimento foi demonstrado pelos respondentes:

O meio ambiente está muito maltratado. Os homens derrubam árvores, sujam e há falta de limpeza. Jogam lixo em qualquer lugar. O povo ainda não tem educação. Precisam ser educados para ter ciência do que fazem.

Por não estar associada a nenhuma variável explicativa, a ideia de que é necessário educar ou ensinar as pessoas a cuidar do meio ambiente é uma concepção sobre o meio ambiente que se distribui entre todos os participantes. Desse modo, pode-se dizer que esse conhecimento permeia o discurso de todos os respondentes, independentemente de qualquer característica particular.

\section{Características do meio ambiente}

A classe número 4 é a maior do corpus, e corresponde a 56 UCEs, o que corresponde a $41 \%$ do total de UCEs analisadas, e não está associada a nenhuma variável explicativa. Seu conteúdo se volta para a descrição do meio ambiente, apontando suas características, como ilustrado pela presença dos elementos seres, natureza, homem e espaço, entre outros.

O conteúdo dessa classe é bastante diverso, tendo em vista sua abrangência, de modo que o meio ambiente é apontado também como um lugar, um espaço, ou mesmo considerado como tudo que nos cerca. Uma resposta ilustra a forma como o meio ambiente foi descrito pelos respondentes:

O meio ambiente é o espaço em que vivemos. Ele engloba diferentes grupos, pessoas, animais, vegetais, etc., bem como a infraestrutura utilizada por esses grupos. Atualmente encontra-se ameaçado em virtude dos excessos cometidos pelo ser humano.

A classe número 4 não está ligada a nenhuma variável explicativa, o que indica que informações sobre as características do meio ambiente estão presentes no conhecimento que todos os respondentes demonstraram possuir sobre a água.

\section{Representação social do meio ambiente em relação à faixa etária}

Embora fosse objetivo deste estudo identificar possíveis diferenças na representação social do meio ambiente de acordo com a faixa etária dos respondentes, a única associação encontrada foi entre as classes 1 e 3 . Desse modo, evidencia-se a tendência das pessoas com 60 anos ou mais de demonstrar 
preocupação com o meio ambiente. As outras classes de pensamento não se associam a nenhuma faixa etária específica, o que indica que o modo de pensar sobre o meio ambiente não recebe forte influência da faixa etária dos respondentes.

\section{Organização da representação}

Como é possível observar na Figura 1, as classes 1 e 3, em uma primeira subdivisão, se opõem às classes 2 e 4 . Ao observar atentamente o conteúdo das classes, torna-se possível entender tal oposição. A classe 1, que trata dos problemas ambientais, e a classe 3, que aborda a educação para o cuidado, relacionam-se ao pensamento ecológico, ligado ao novo paradigma ambiental. Já a classe 2, que considera o papel do meio ambiente para manutenção da vida, e a classe 4, que trata das características do meio ambiente, estão ligadas ao paradigma antropocêntrico, em que o meio ambiente é responsável pelo provimento das necessidades humanas.

\section{Fontes de informação sobre o meio ambiente}

Como forma de identificar a origem das informações que os participantes possuíam sobre o meio ambiente, foi apresentado um quadro de possibilidades em que deveriam ser assinaladas as fontes de informação considerando a quantidade de informações recebidas de cada fonte; os respondentes deveriam assinalar entre a maioria, algumas e nenhuma. Os itens pesquisados foram: jornais e revistas, escola, amigos, televisão, folhetos explicativos, família e outros, nesse caso, pedindo-se especificações.

A fonte de informação mais importante para a maioria da amostra foi a televisão, seguida pelos jornais e revistas. Em terceiro lugar como fonte de informação responsável pelos conhecimentos sobre o meio ambiente, está a escola; família e amigos são responsáveis por algumas informações para mais de $50 \%$ dos respondentes. As demais fontes de informação se mostraram menos importantes. O Gráfico 1 demonstra tais informações:

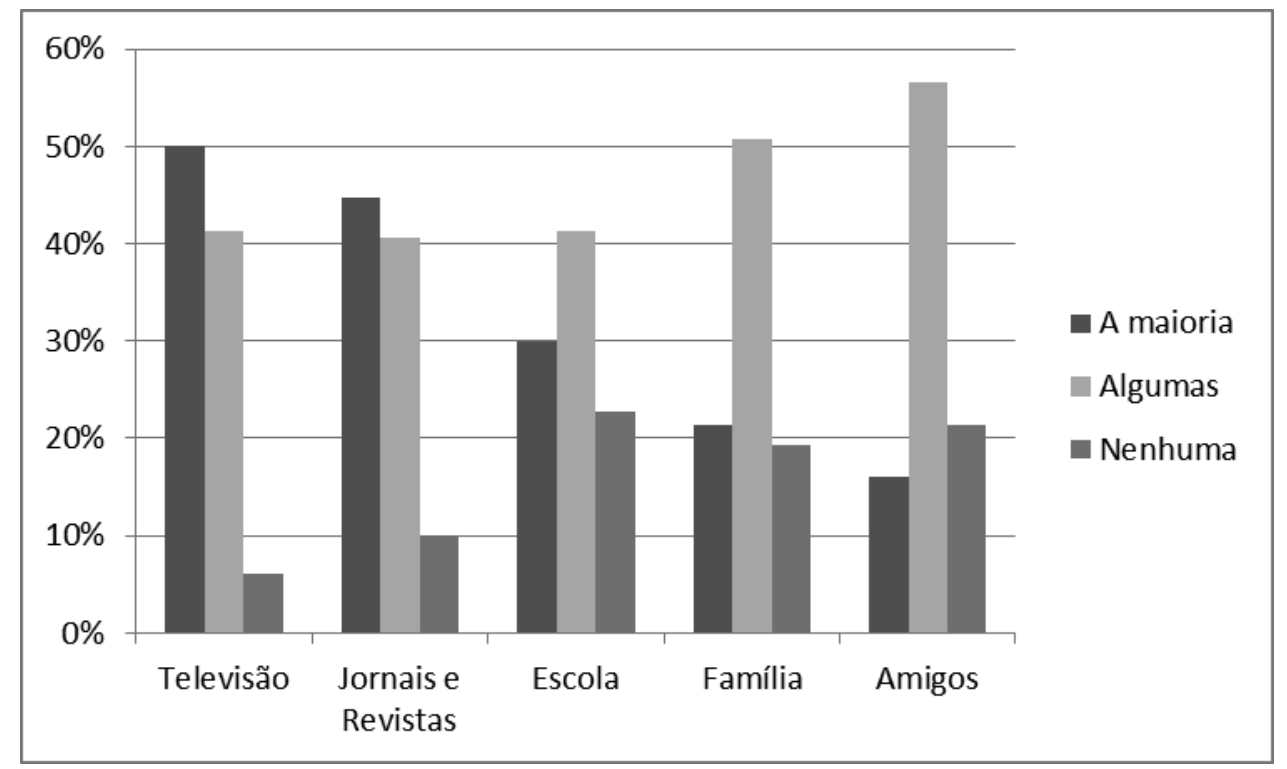

Gráfico 1. Fontes de informação sobre o meio ambiente 


\section{Representações sociais da água}

Para identificação do conteúdo da representação social da água, foi realizada uma análise semelhante àquela descrita sobre o meio ambiente. Será apresentado, a seguir, o dendograma da classificação hierárquica descendente sobre a representação social da água para identificação das classes, conforme a Figura 2.

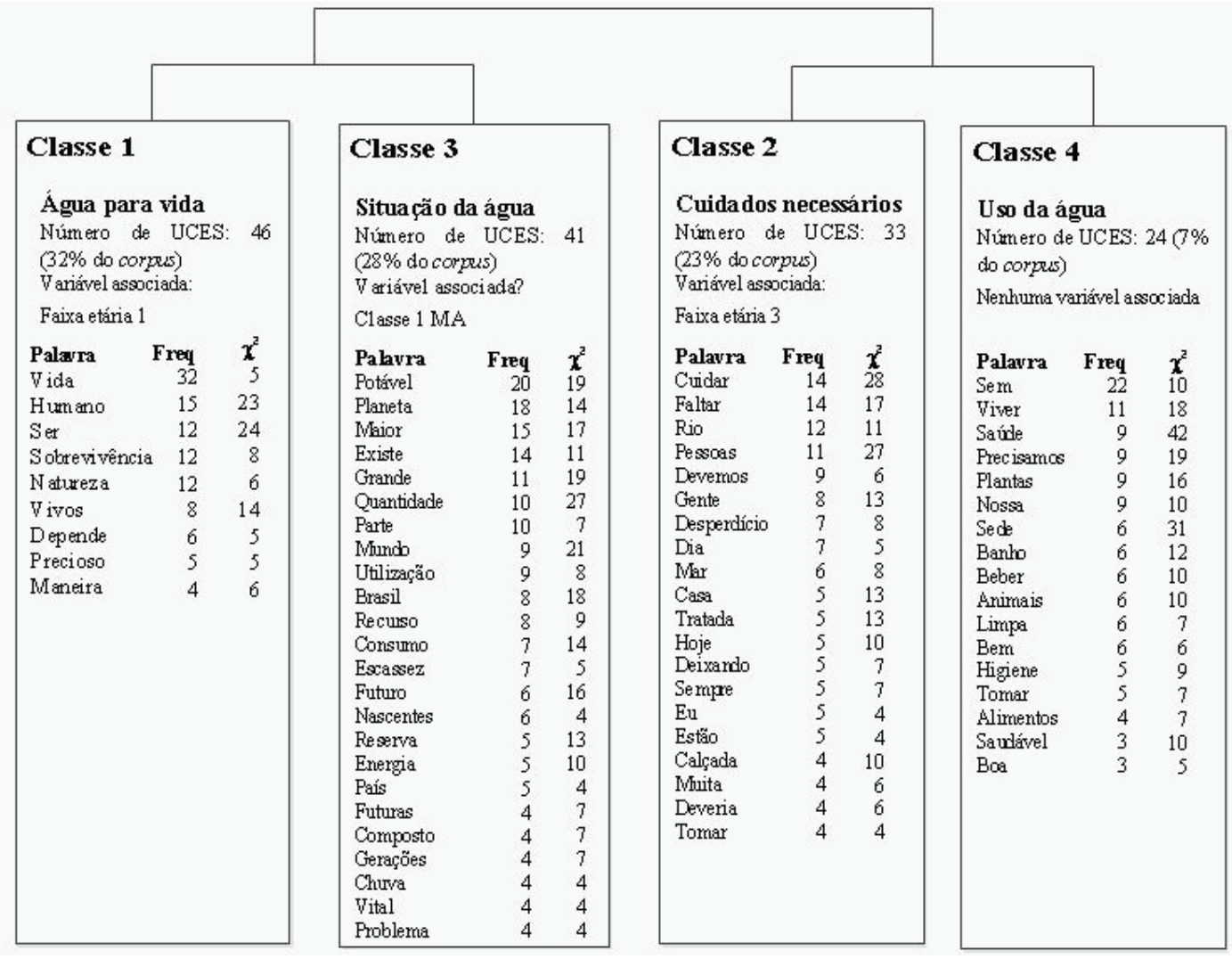

Figura 2. Dendograma da análise hierárquica descendente sobre as informações dos respondentes sobre a água

\section{Água necessária à manutenção da vida}

Essa classe coloca em pauta uma representação social da água focada na sua importância para a manutenção da vida e para a sobrevivência de todos os seres sobre a face da Terra. Considerada um bem primordial, seu papel é destacado e sua valorização se torna evidente. Alguns recortes das respostas encontradas ilustram esse conhecimento:

A água é essencial para a sobrevivência de todos os seres vivos. O ser humano possui em seu corpo mais de $60 \%$ de água.

A água é de extrema importância não apenas para os seres humanos, que dependem dela para a sobrevivência, mas também para a natureza em geral, como as plantas e animais, que precisam de água para sobreviver. 


\section{Água que precisa de cuidados}

Através da análise dessa classe, é possível identificar algumas preocupações com o cuidado que a água deveria receber e a preocupação com a possibilidade de que um dia a água possa faltar. Um trecho de resposta ajuda a compreender tais preocupações:

A água é necessária para todos. Infelizmente, ela não vem sendo tratada adequadamente como deveria. A água, muitas vezes, está em falta nas residências.

\section{Situação da água no Brasil e no mundo}

O conteúdo dessa classe remete às informações sobre a quantidade de água doce e potável disponível no Brasil e no mundo. Um trecho de resposta ilustra a forma como esse conhecimento foi demonstrado pelos respondentes:

Quanto à água potável, ela faz parte de 3 a $5 \%$ da água no mundo. O Brasil é uma das maiores fontes do Planeta. As geleiras do Planeta possuem cerca de 50 a $60 \%$ da água potável.

\section{Uso da água}

Seu conteúdo se volta para o uso que é feito da água, especialmente em tarefas cotidianas. A presença de elementos como sede, banho, higiene, beber e tomar, entre outros, demonstram essas características. A água também é considerada promotora de saúde, o que é destacado pelas palavras saúde e saudável. Algumas respostas ilustram essa forma de pensar sobre a água:

A água é muito importante para a nossa saúde do dia a dia e também é muito importante para os animais, plantas, higiene bucal, para beber, tomar banho e fazer a nossa alimentação.

Sem água, não tem comida; sem água, não tomamos banho, etc. Devemos tomar água todos os dias, porque faz muito bem para nós todos.

\section{Organização da representação}

Como é possível observar na Figura 2, as classes 1 e 3, em uma primeira subdivisão, se opõem às classes 2 e 4 . Ao observar atentamente o conteúdo das classes, tornase possível entender tal oposição. A classe 1, que cita a importância que a água possui para a manutenção da vida, e a classe 3, que trata da situação da água, demonstram uma visão pautada nas informações. Na classe 1 , o discurso midiático é reproduzido sem muita reflexão, e, na classe 2, são reproduzidos conhecimentos sobre a situação da água que correspondem à demanda apresentada, já que a pergunta era voltada para o saber. Já a classe 2, que lembra a necessidade de cuidar da água, e a classe 4, que trata do uso cotidiano do recurso, estão ligadas ao cotidiano, e são pautadas na experiência adquirida diariamente ou nos cuidados introduzidos nesse cotidiano para manter a qualidade e a disposição do recurso.

\section{Relações entre as representações sociais do meio ambiente e da água}

Para identificar as possíveis relações entre as representações sociais da água e do meio ambiente, de acordo com o seu conteúdo, foi realizada uma análise de contraste com o auxílio do programa ALCESTE. Nessa etapa de análise, o conteúdo produzido em resposta à questão aberta sobre as informações mais importantes que os respondentes possuíam sobre a água foi comparado com o resultado obtido através da classificação hierárquica 
descendente realizada em relação ao meio ambiente. Os respondentes foram classificados de acordo com a classe de respostas que apresentaram quanto à questão sobre as informações que possuíam sobre o meio ambiente. Desse modo, uma nova variável foi adicionada à linha de comando do corpus sobre a água, a classe em que o respondente foi enquadrado relativa ao meio ambiente, que variou de classe 1 até classe 4.

Verificou-se que, dentre as 149 UCEs iniciais do corpus sobre o meio ambiente, 137 foram retidas, de modo que $137 \mathrm{UCls}$, ou 137 sujeitos, do corpus sobre a água foram classificados de acordo com suas respostas sobre o meio ambiente.

A Tabela 1 ilustra as palavras com maior associação a cada uma das classes do meio ambiente, mostrando algumas relações estabelecidas entre o conteúdo da representação social da água e do meio ambiente.

Tabela 1. Resultados da análise de contraste por classe em relação ao meio ambiente

\begin{tabular}{|c|c|c|c|c|c|}
\hline \multicolumn{3}{|c|}{$\begin{array}{c}\text { Classe } 1 \mathrm{MA} \\
\text { Problemas ambientais }\end{array}$} & \multicolumn{3}{|c|}{$\begin{array}{c}\text { Classe } 2 \mathrm{MA} \\
\text { Importante para a vida }\end{array}$} \\
\hline Palavra & Freq. & $x^{2}$ & Palavra & Freq. & $x^{2}$ \\
\hline Casa & 4 & 13 & Essencial & 7 & 8 \\
\hline Banho & 5 & 8 & Muita & 4 & 6 \\
\hline Onde & 3 & 6 & Humano & 8 & 6 \\
\hline Higiene & 4 & 6 & Todos & 13 & 4 \\
\hline Dia & 4 & 4 & Fonte & 8 & 4 \\
\hline \multirow[t]{3}{*}{ Lavar } & 4 & 4 & Poluição & 7 & 4 \\
\hline & & & Necessário & 4 & 4 \\
\hline & & & Quantidade & 5 & 4 \\
\hline \multirow{2}{*}{\multicolumn{3}{|c|}{$\begin{array}{c}\text { Classe } 3 \mathrm{MA} \\
\text { Educar para cuidar }\end{array}$}} & \multirow{2}{*}{\multicolumn{3}{|c|}{$\begin{array}{l}\text { Classe } 4 \text { MA } \\
\text { Caracterìsticas }\end{array}$}} \\
\hline & & & & & \\
\hline Palavra & Freq. & $x^{2}$ & Palavra & Freq. & $\chi^{2}$ \\
\hline Nada & 4 & 5 & Maior & 14 & 8 \\
\hline Banho & 5 & 5 & Parte & 11 & 7 \\
\hline Nossos & 5 & 5 & Utiliza & 9 & 4 \\
\hline
\end{tabular}

Os respondentes que deram destaque aos problemas ambientais (classe 1) representaram a água como um elemento que está perdendo sua qualidade e tornando-se um bem escasso:

Temos conhecimento de que a água potável está terminando, que as geleiras estão descongelando, as marés estão subindo, e estão causando transtornos. Na minha casa, temos consciência do que está acontecendo, evitamos o desperdício.

Na classificação hierárquica descendente, verificou-se que a classe 1 do meio ambiente problemas ambientais - está associada à classe 2 da água - água que precisa de cuidados. Desse modo, pode-se considerar que as pessoas que se preocupam com os problemas ambientais também consideram que a água precise de cuidados. 
Quando o meio ambiente foi considerado um elemento importante para a vida (classe 2), a situação da água no Brasil e no mundo recebeu destaque por parte dos respondentes, bem como a importância da água para a manutenção da vida.

O Brasil é um país onde existe a maior reserva de água potável. Aqui temos o famoso aquífero guarani, que vem desde o Rio de Janeiro por toda a Região Sudeste e Sul, indo até outros países do Mercosul.

A água é essencial para todos os seres vivos, por isso devemos passar para o outro o respeito da economia, da não poluição e muito mais, já que estamos em um país rico em se tratado de água. Devemos nos preocupar.

Nenhuma associação entre a classe 2 do meio ambiente e as classes da água foi evidenciada na classificação hierárquica descendente realizada com o corpus sobre a temática da água. No entanto, pode-se dizer que as pessoas que consideram o meio ambiente importante para a vida também destacam a situação da água no Planeta, esboçando uma associação entre as classes 3 da água e 2 do meio ambiente. Da mesma forma, também destacam a água como necessária para a vida, de modo que a classe 1 da água também está associada à classe 2 do meio ambiente.

A classe 3 do meio ambiente, em que a necessidade da educação para o cuidado como meio ambiente foi destacada, está associada a uma representação da água voltada ao seu valor para a manutenção da vida:

Que ela é responsável pela vida aqui existente, que sem água e ar não tem vida.

Devemos dar valor à água, principalmente à água tratada. Ninguém nem nada sobrevive sem água.

Já os respondentes que enumeraram características do meio ambiente (classe 4) apontaram a situação da água no Brasil e no mundo:

A água cobre aproximadamente $71 \%$ da superfície da Terra, porém, apenas 3\% são próprias para o consumo, o que nos mostra que, em breve, a água será a moeda de troca no mundo.

Ainda que incialmente não tenha sido verificada nenhuma relação entre as classes 4 do meio ambiente - características - e classe 3 da água - situação da água no Brasil e no mundo, a análise de contraste evidenciou uma possível associação entre tais formas de avaliar a água e o meio ambiente.

Através da análise de contraste realizada no corpus sobre a temática da água com a inserção da variável classe sobre o meio ambiente, foi possível identificar possíveis relações entre os modos de considerar os dois elementos. Desse modo, sintetizando os resultados encontrados evidenciaram-se algumas associações entre os modos de pensar sobre a água e o meio ambiente, conforme a Figura 3:

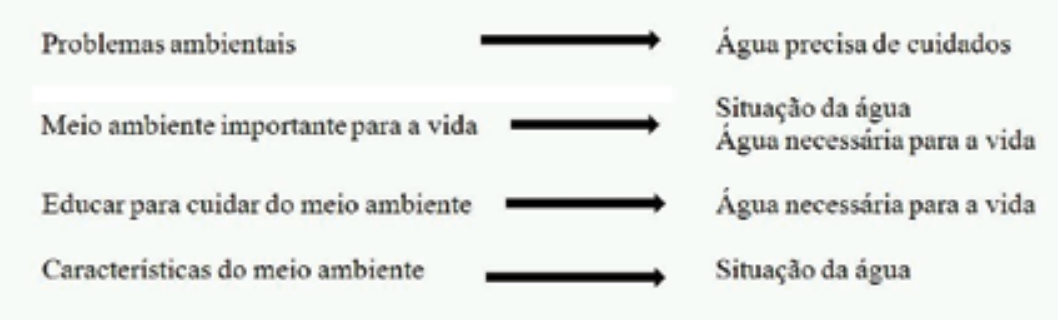

Figura 3. Associações entre as classes da representação social da água e da representação social do meio ambiente 
É importante considerar que se trata de tendências, e sugere-se que as pessoas que pensam sobre o meio ambiente de determinada forma tendem a considerar a água de maneira condizente com essa forma.

\section{Discussão}

Estudos anteriores sobre a representação social do meio ambiente (Martinho \& Talamoni, 2007; Nascimento-Schulze, 2000; Reigota, 2004) identificam uma representação naturalista do meio ambiente como a visão que mais recebe destaque. É importante perceber que o primeiro estudo foi realizado nos anos 90 (Reigota, 2004), o segundo no ano 2000 (Nascimento-Schulze, 2000), e que o terceiro é mais recente (Martinho \& Talamoni, 2007). O estudo ora apresentado identificou novamente a predominância de tal representação sobre o meio ambiente, pois a representação denominada naturalista se mostrou presente, coincidindo com o conteúdo da classe 4 - características do meio ambiente -, que representou $41 \%$ do corpus. As demais classes apresentam informações diferentes dos estudos já referidos. Aqui se fez presente a identificação de problemas ambientais, a importância do meio ambiente para a manutenção da vida e a necessidade de educação para preservar o meio ambiente.

É importante lembrar que este estudo procurou identificar a dimensão informacional da representação social do meio ambiente. A questão apresentada aos participantes se referia ao que sabiam sobre o meio ambiente, não thes tendo sido perguntado o que pensavam sobre o tema, o que se reflete no conteúdo explicitado, de modo que não se pode dizer que as representações encontradas difiram das representações sociais do meio ambiente encontradas em estudos anteriores, mas pode-se dizer que, neste estudo, é apresentada uma dimensão específica de tal representação, a informacional, que reflete o conteúdo representacional já identificado em alguns estudos. Em uma pesquisa realizada no México por López, Avelar, Moreno, Beltrán e Estrada (2008) com o objetivo de conhecer as representações sociais da água de adolescentes estudantes e de pais de família, verificou-se que o elemento vida possui um importante papel, principalmente no discurso dos pais, o que indica que esse é um elemento central na representação da água. Dados semelhantes foram encontrados por Polli (2008), que identificou o elemento vida como principal na representação social da água entre lideranças locais envolvidas com o manejo do recurso natural. Outros elementos de destaque foram: preservação e responsabilidade humana pelo cuidado com o recurso.

A dimensão informacional da representação social identificada neste estudo reforça a ideia de que a água é um elemento essencial para a manutenção da vida, além de considerar que precisa ser cuidada, o que corrobora o conteúdo já encontrado por estudos anteriores. Talvez ainda por se tratar das informações que os respondentes possuíam sobre o recurso, receberam destaque seus usos e a situação da água no Brasil e no mundo, em termos de qualidade e de disponibilidade.

Também foi possível verificar uma possível relação entre os conteúdos representacionais da água e do meio ambiente através da comparação das respostas a duas diferentes questões apresentadas aos respondentes. A associação identificada aponta uma tendência de pensamento.

Desse modo, pode-se afirmar que as pessoas que consideram a água um recurso natural que demanda cuidados tendem a apresentar preocupações com os problemas ambientais. Talvez isso se deva ao pensamento corrente na sociedade de que a qualidade e a 
disponibilidade da água são atualmente, ou tendem a se tornar no futuro, alguns dos problemas ambientais mais graves que a população da Terra enfrenta ou irá enfrentar (Barcellos, Rocha, Rodrigues, Costa, Silva, Moraes, et al., 2006; loris, 2008).

De maneira semelhante, as pessoas que consideram o meio ambiente relevante para a continuidade da vida na Terra tendem a demonstrar que têm conhecimento da situação da água no Planeta em termos de quantidade e qualidade, além de considerar a sua relevância para a manutenção da vida. Ao avaliar a água como um elemento natural fundamental, a ligação entre a importância do meio ambiente e a da água para a preservação da vida adquire um caráter lógico, e talvez devido a essa importância que o elemento recebe as pessoas se preocupem em conhecer suas condições no momento atual. Além disso, as pessoas que julgam a água elemento essencial à vida tendem a pensar que haja a necessidade de educação para o cuidado com o meio ambiente.

A ultima relação que pode ser identificada entre as representações sociais do meio ambiente e da água se refere principalmente ao aspecto informacional da representação. As pessoas que apontaram características do meio ambiente também se preocuparam em apontar a situação da água no Brasil e no mundo, tanto em termos de disponibilidade quanto de qualidade, tendo seguido estritamente as indicações da pergunta ao falar sobre as informações que possuíam a respeito das duas temáticas expostas.

\section{Conclusões}

Este estudo pretendeu identificar a dimensão informacional das representações sociais do meio ambiente e da água, além de relações entre tais conhecimentos. Importa conhecer a dimensão informacional de uma representação social, pois tal conhecimento permite identificar a apreensão que as pessoas têm do saber cientifico que lhes chega através da educação formal, através da mídia ou mesmo que ganham forma na comunicação social. Desse modo, pode-se perceber a forma como as pessoas se apropriam do conhecimento que circula na sociedade.

No entanto, deve-se ressaltar que, quando se fala em dimensões de uma dada representação social, isso é feito de modo didático, pois, já que o pensamento não separa imagens de saberes ou de atitudes, o pensamento social mistura as três dimensões na formulação das representações sociais. Assim, ao responder a questões sobre o que se sabe sobre o meio ambiente ou a água, as pessoas incluíram em suas respostas outras dimensões dessas representações, e o que se apresentou neste estudo não foi apenas a dimensão informacional da representação social do meio ambiente e da água.

Considera-se que cada uma das representações estudadas foi identificada de maneira global, e a dimensão informacional esteve mais presente em uma das classes de cada uma das representações com um destaque maior, provavelmente porque alguns respondentes estiveram mais presos à questão inicial. $\mathrm{Na}$ representação social do meio ambiente, isso aconteceu em relação à classe que aborda as características do meio ambiente, em que os respondentes se preocuparam em descrevê-lo. Na representação social da água, é possível constatar a intenção de tratar desse saber na classe em que a situação da água no Brasil e no mundo recebe destaque. Essas classes expressam melhor a dimensão informacional da representação, no entanto, as três dimensões se mostram presentes em todas elas, de modo que este estudo, a despeito de suas intenções iniciais, terminou por identificar o conteúdo representacional do meio ambiente e da água e algumas relações entre elas. 


\section{Gislei Mocelin Polli}

Doutora em Psicologia pela Universidade Federal de Santa Catarina e docente da Faculdades Borges de

Mendonça, Florianópolis - SC - Brasil.

E-mail: gismocelin@gmail.com

\section{Brigido Vizeu Camargo}

Doutor em Psicologia Social pela École des Hautes Études en Sciences Sociales e docente da Universidade Federal de Santa Catarina, Florianópolis - SC - Brasil.

E-mail: brigido.camargo@yahoo.com.br

Endereço para envio de correspondência:

Rua Salvatina Feliciana dos Santos, 263, Ap. 202a , Itacorubi. CEP: 88034-600. Florianópolis, SC"

Recebido 25/08/2011, Aprovado 29/11/2012.

Referências
Abric, J. C. (1994). Pratiques sociales, représentation sociales. In J. C. Abric (Ed.). Pratiques sociales \& représentations (pp. 217-238). Paris: Press Universitaires de France.

Barcellos, C. M., Rocha, M., Rodrigues, L. d. S., Costa, C. C., Silva, I. J. d., Moraes, E. F., et al. (2006). Avaliação da qualidade da água e percepção higiênico-sanitária na área rural de Lavras, Minas Gerais, Brasil. Cadernos de Saúde Pública, 22(9), 1967-1978.

Camargo, B. V. (2005). Alceste: um programa informático de análise quantitativa de dados textuais. In A. S. P. Moreira, B. V. Camargo, J. C. Jesuíno \& M. N. Sheva (Orgs.). Perspectivas teórico-metodológicas em representações sociais (pp. 511539). João Pessoa, PB: Editora Universitária UFPB.

Félonneau, M. L. (2003). Les représentations sociales dans le champ de l'environnement. In G. Moser \& K. Weiss (Eds.). Espaces de vie: aspects de la relation homme-environnement (pp. 145-176). Paris: Armand Colin.

Guimelli, C. (1993). Concernig the structure of social representations. Papers on Social Representations, 2(2), 85-92.

loris, A. A. R. (2008). Águas que não correm mais pro mar. Interações, 9, 9-17.

Jodelet, D. (1996). "Las representaciones sociales del medio ambiente", In L. Iñiguez \& E. Pol (Eds.) Cognición, representación y apropriación del espacio. Monografias Psicosocio-ambientales. (pp. 29-44). Barcelona: Publicaciones de la Universitat de Barcelona.

Jodelet, D. (2001). Representações sociais: um domínio em expansão. In D. Jodelet (Ed.). As representações sociais (pp. 17-44). Rio de Janeiro: EdUERJ.

Jodelet, D. (2002). A cidade e a memória. In V. Del-Rio, C. R. Duarte \& P. A. Rheingantz (Eds.). Projeto de lugar: colaboração entre psicologia, arquitetura e urbanismo (pp. 31-43). Rio de Janeiro: Contra capa.

López, T. M. T., Avelar, R. S., Moreno, M. P., Beltrán, C. A., \& Estrada, J. G. S. (2008). Vida, frescura y limpieza: representaciones sociales del agua desde el punto de vista de adolescentes y de padres de familia. Medio ambiente y comportamiento humano, 9(1, 2), 171-195.
Martinho, L. R., \& Talamoni, J. L. B. (2007). Representações sobre meio ambiente de alunos da quarta série do ensino fundamental. Ciência \& Educação, 13, 1-13.

Moscovici, S. (1978). A representação social da psicanálise. Rio de Janeiro: Zahar

Moscovici, S. (1982). On social representation. In J. P. Forgas (Ed.). Social cognition (pp. 181-209). Londres: Academic Press.

Moser, G., Ratiu, E., \& Vanssay, B. (2005). Pensar en el água: representaciones sociales, ideologías y práticas: un modelo de las relaciones con el agua en diferentes contextos societales. Trayectorias, 7(18), 79-91.

Nascimento-Schulze, C. M. (2000). Representações sociais da natureza e do meio ambiente. Revista de Ciências Humanas, (Esp.), 67-81.

Nascimento-Schulze, C. M., Fragnani, E. F. S., Carboni, L. R., \& Maliska, M. E. (2002). Atitudes frente ao novo paradigma ambiental: um estudo no contexto turístico de Florianópolis. Revista de Ciências Humanas, (Esp.), 215-224.

Pinheiro, J. Q. (2003). Psicologia ambiental brasileira no início do século XXI: sustentável? In O. H. Yamamoto \& V. V. Gouveia (Eds.). Construindo a psicologia brasileira: desafios da ciência e prática psicológica (pp. 279-313). São Paulo: Casa do Psicólogo.

Polli, G. M. (2008). Representações sociais da água e tecnologias sociais. Dissertação de Mestrado, Universidade Federal de Santa Catarina, Florianópolis, SC.

Reigota, M. (2004). Meio ambiente e representação social. São Paulo: Cortez.

Silva-Filho, J. C. L.; Gavronski, I.; Oliveira, J.M.; Tocchetto, M. R. Araújo, N. R. S.; Torres, F. S. Poledna, S. R. C. (2007). Análise comparativa do novo paradigma ecológico em dois estados brasileiros: a gestão ambiental além do mercado e do estado. Anais do ENGEMA - Encontro Nacional de Gestão Empresarial e Meio Ambiente, Curitiba, PR , 9. 